\title{
Anti-CD45 Monoclonal Antibody
}

National Cancer Institute

\section{Source}

National Cancer Institute. Anti-CD45 Monoclonal Antibody. NCI Thesaurus. Code C70798.

A monoclonal antibody directed against the receptor-like leukocyte cell surface glycoprotein CD45 with leukocyte-depleting activity. Upon administration, anti-CD45 monoclonal antibody binds to leukocyte surface-expressed CD45, which may result in the transient depletion of circulating leukocytes including circulating $T$ cell depletion (TCD). CD45, a receptor-like protein-tyrosine phosphatase that consists of several isoforms, is present on all differentiated hematopoietic cells except erythrocytes and plasma cells and is essential for T cell development and lymphocyte activation. 